\title{
The Application of Macroprudential Capital Requirements in Managing Systemic Risk
}

\author{
Hong Fan (D), Chirongo Moses Keregero, and Qianqian Gao \\ Glorious Sun School of Business and Management, Donghua University, Shanghai 200051, China \\ Correspondence should be addressed to Hong Fan; hongfan@dhu.edu.cn
}

Received 4 July 2017; Revised 15 December 2017; Accepted 21 December 2017; Published 22 January 2018

Academic Editor: Ahmet Sensoy

Copyright (C) 2018 Hong Fan et al. This is an open access article distributed under the Creative Commons Attribution License, which permits unrestricted use, distribution, and reproduction in any medium, provided the original work is properly cited.

\begin{abstract}
When setting banks regulatory capital requirement based on their contribution to the overall risk of the banking system we need to consider that the risk of the banking system as well as each banks risk contribution changes once bank equity capital gets redistributed. Therefore the present paper provides a theoretical framework to manage the systemic risk of the banking system in Nigeria based on macroprudential capital requirements, which requires banks to hold capital that is proportional to their contribution to systemic risk. Using a sample of 10 Nigerian banks, we reallocate capital in the system based on two scenarios; firstly in the situation where the system shocks do not exist in the system, we find that almost all banks appear to hold more capital; secondly, we also consider the situation where the system shocks exist in the system; we find that almost all banks tend to hold little capital on four risk allocation mechanisms. We further find that despite the heterogeneity in macroprudential capital requirements, all risk allocation mechanisms bring a substantial decrease in the systemic risk. The risk allocation mechanism based on $\Delta$ CoVaR decreases the average default probability the most. Our results suggest that financial stability can be substantially improved by implementing macroprudential regulations for the banking system.
\end{abstract}

\section{Introduction}

The downfall of Lehman Brothers in mid-2008 unveils that the modern financial system was extremely fragile. The financial system deteriorated due to the distress and in some cases failure of important institutions, leading to further distress and the spread of shocks to the real economy [1]. The crisis emphasizes the need of identifying the underlying factors that destabilize the financial institutions, which could result in systemic risk.

Bisias et al. [2] have defined systemic risk as the risk of disruption to financial services that is caused by an impairment of all or parts of the financial system and has the potential to have serious negative consequences on the real economy. Systemic risk is created endogenously within the banking system due to banks' common exposures to macroeconomic factors and propagated through interbank connections (contagion); thus systemic risk encompasses two aspects which are basic and contagious defaults.

To deal with the systemic risk better, the financial stability board has pinpointed the need for a macroprudential approach to financial system analysis. Researchers like Galati and Moessner [3], Cerutti et al. [4], Ebrahimi Kahou and Lehar [5], Lehar (2005) [6], and Hanson et al. [7] argue that macroprudential policy is aimed to mitigate the systemic risk and reduce its aggregate cost for the real economy; thus the bank regulation should be designed on macroprudential perspective so as to downsize the amount of systemic risk. On the other hand, Basel III requires a capital conservation buffer in normal times consisting of a further amount of core Tier 1 equity capital equal to $2.5 \%$ of risk weighted assets. This provision is designed to ensure that banks build up capital during normal times so that it cannot be affected when losses are incurred during periods of financial distress. Therefore it is much easier for banks to raise capital during normal times than during periods of stressed market conditions. In a situation where the capital conservation buffer has been wholly or partially used up, banks are required to constrain their dividends until the capital has been replenished. However, the bank regulators in some countries require banks to hold more capital than the minimum specified by the Basel Committee and some banks themselves have a target for the 
capital they will hold that is higher than that specified by their bank supervisors.

In a banking system both the overall risk and each bank's contribution are endogenous and hinge on the banks' equity capital. This means that as banks hold more capital the probability of default through either direct losses or contagion is less; therefore redistributing bank capital changes the banks' default probabilities, overall risk of the banking system, and each bank's risk contribution. In this work we investigate one regulatory mechanism that is macroprudential capital requirements that require each bank to hold a buffer of equity capital that corresponds to the banks contribution to the overall risk of the system. We use the complex network theory to construct the network model of banking system, where each bank is regarded as a node and connected with others through the interbank bilateral exposures. We investigate the systemic risk of banking system by measuring bank's basic default caused by the insolvency of bank itself and contagious default due to the interbank bilateral exposures.

We derive macroprudential capital requirements as a fixed point using four risk allocation mechanisms: Component and incremental value at risk [8], $\Delta \mathrm{CoVaR}$ [9], and a risk allocation mechanism based on Shapley value [10]. Among the mentioned approaches, CoVaR has the ability to detect the risk on the system by individually systemically important financial institutions, which are so interconnected and large that they can cause negative risk spillover effects on others and in addition to the smaller institutions that are systemic when acting as part of a crowd. Moreover this measure does not rely on contemporaneous price movements and therefore can be used to anticipate systemic risk as it captures institutional externalities such as "too big to fail," "too interconnected to fail," and crowded trade positions. We show that reallocation of bank capital in the system through the new capital requirements can change the probability of the bank to default and change total systemic risk. We supplement the model by applying the interbank clearing network algorithm designed by Eisenberg and Noe [11]. Finally, we compare the effects of macroprudential regulations for banking system under four risk allocation mechanisms to measure the stability of the banking system.

Our study considers Africa that is mostly excluded by researchers in the study of systemic risk because its stock market capitalization is low in the global banking assets. We use the data of 10 major banks in Nigeria in terms of assets value and test its validity even though the country was not affected heavily by the financial crisis. Moreover this study is intended to show if banks keep enough capital for the risks they take and therefore we estimate macroprudential capital requirements as a fixed point problem. Thus, supported by both theoretical and empirical evidence in Nigerian banking system, our studies analyze how macroprudential capital requirements can reduce the level of systemic risk.

\section{Literature Review}

There has been a wide heterogeneous discussion of measuring and evaluating contagion and systemic risk around the globe; however there is a scant of literature reviews on the macroprudential policy particularly regulatory capital requirements on managing of systemic risk. The main impediment for a true implementation of macroprudential capital requirements is that each bank's capital requirement would in part be driven by the actions of other banks, and therefore a bank cannot exercise full control over its own capital requirements.

Two types of the risk of contagion have been studied in the literature. One is the network of banks investing in similar types of assets, in which one bank failure can lead to a fall in the price of its assets and then affect the solvency of other banks that hold the same assets $[12,13]$. The other is the risk of contagion in the interbank market, which concerns the liquidity risk of contagion at a form of interlocking exposure; such exposure is very short term, mainly overnight. In this study we focus on the interbank network as a contagion channel of systemic risk, which is when some banks are not able to honor their promises in the interbank market they might push other banks into insolvency which might again lead to defaults of other banks.

The literature on contagion starts with the work of Allen and Gale [14] who give a model of risk propagation through interbank exposure network. They consider that the possibility for contagion depends on the precise structure of the interbank market and show that a complete structure of claims in which every bank has symmetric exposures to all other banks is much more stable than an incomplete structure; thus for same shocks some structures would result in contagion while others would not. Freixas et al. [15] consider that for contagion to happen in a system with money-centre banks where the institutions on the periphery are connected to banks at the centre but not to each other depends on the precise values of the models parameters. Researchers regard financial networks as robust-yet-fragile which means that they can absorb smaller shocks to the system but may show contagion and cascade effects when exposed to a large enough shock [16-18]. Allen and Gale [14] show that if there is no liquidity shock, all banks can survive; however in liquidity shock case, number of defaulting banks change depending on network completeness. Upper [19] makes a summary of contagion studies in the literature and shows that as the shock some papers are considering individual bank failures and some are using failure of group of banks. Lubloy [20] grouped banks according to their FX exposures and let all banks in a given category fail jointly. Elsinger et al. [21] use loan registry data to model common shocks to loan books and banks foreign exchange and stock market exposures to model shocks from financial markets. Their approach included bankruptcy costs in the simulation of the Austrian banking system and show that the system is able to absorb shocks well for small bankruptcy costs while large dead weight losses can crash the banking system. Rogers and Veraart [22] model clearing in the interbank networks with bankruptcy costs and provide an analysis of those situations in which banks have incentives to bail out distressed bank. Moreover, Frisell et al. [23] use detailed Swedish data to model common shocks; they use asset prices correlations to get a covariance matrix for the shock process. They show 
that contagion is much more common and reflected in the Swedish banking system. Caccioli et al. [24] model common shocks emanating from overlapping securities portfolios. Their study reveals that, upon bank default, when the threat of contagion looms, other banks might be in weak position as well making them more vulnerable to contagion. Gauthier et al. [25] model loan losses of banks using detailed information on banks' loan books and common industry exposures and follow an iterative procedure in which they compute each bank's risk contribution, adjust the bank's capital level to that risk contribution, and then recompute both systemic risk and each bank's risk contribution. Furfine [26] considers the effect of liquidity in the contagion process in the case where the largest lender in the federal funds market is unable to lend, therefore forcing its counterparties of that institution to look elsewhere for funds or reduce their own lending.

Several studies have also examined the empirical features of interbank networks in various countries such as Upper and Worms [27] in Germany, van Lelyveld and Liedorp [28] in the Netherlands, Wells [29] in the UK, and Mistrulli [30] in Italy. These studies have revealed the heterogeneity of interbank network and are systematically surveyed in [19].

A number of studies have examined the dynamic model of network structure such as Georg [31] who developed a dynamic model of a banking system that can be used to analyze the impact of the interbank network structure on financial stability in way that when depositors decide on deposit investment via a random walk process, banks pay their maturing loans depending on their liquidity position. Lux [32] examined the dynamic model of interbank credit relationships. He assumed that banks initially choose potential trading partners randomly but form preferential relationships via an elementary reinforcement learning algorithm. The dynamic evolution of the system showed a formation of a core-periphery structure with mainly the largest banks assuming the roles of money centre banks mediating between the liquidity needs of many smaller banks, On the other hand $\mathrm{Xu}$ et al. [33] developed a dynamic network model based on agent behavior to explain the formation mechanism of interbank market and found that the interbank network structure keeps dynamic stability in the network evolution process, while Bluhm et al. [34] built a dynamic banking system with banks optimizing decisions and market adjustment; they found that higher liquidity requirements result in more concentrated network and lower systemic risk.

In our study we believe that deriving macroprudential capital requirements should take into account the dynamic evolution of the banking system when measuring the systemic risk of the banking system. Therefore, we extend the Eisenberg-Noe framework [11] to a dynamic multiperiod. Besides, the total asset value and equity value of the bank change dynamically, which can be estimated from realworld data instead of theoretical assumption. Furthermore, for shock scenarios, we add a system shock artificially in the system to observe the time evolution of the banking system; hence measure the systemic risk and then adjust macroprudential capital requirements according to each bank contributing to the whole system risk. We take into account two scenarios, namely, where the system shocks exist and do not exist in the banking system. For shock scenarios, we measure the systemic risk by checking whether a bank system can withstand certain strength of system shocks. Some banks may be bankrupt at a certain time point due to this artificially added system shock; therefore both the structure and the state of the bank change dynamically. We measure the systemic risk by recording the number of banks which undergo bankruptcy during the time. If the strength of the system shock is fixed, then a bank system with more banks which undergo bankrupt during the whole time course of its evolution is believed to suffer more systemic risk. Moreover we highlight that changing capital requirements change the risk in the banking system and that macroprudential capital requirements have to be seen as a fixed point problem.

The rest of the paper is organized as follows. Section 3 provides the network model of the banking system which encompasses methodology for estimating the matrix of bilateral exposures, the process of estimating the time evolution of balance sheet in the banking system, the methods of estimating the time evolution of bank's default, and the methodology of calculating bank's macroprudential capital. Section 4 provides the macroprudential capital requirements under different risk allocation mechanisms, Section 5 provides data used, Section 6 presents the results, and lastly Section 7 provides the concluding remark.

\section{The Network Model of Banking System}

We use the complex network theory to construct the network model of banking system, where each bank is regarded as a node and connected with others through the interbank bilateral exposures. We investigate the systemic risk of banking system by measuring bank's basic default caused by the insolvency of bank itself and contagious default due to the interbank bilateral exposures. We show explicitly that reallocation of bank capital in the system through the new capital requirements can change the probability of the bank to default and change total systemic risk. Thus we set the macroprudential capital requirements as a fixed problem and use four risk allocation mechanisms to compute bank's macroprudential capital requirements. We also compare the effects of macroprudential regulations for banking system under four risk allocation mechanisms which help us to measure the stability of the banking system. Figure 1 illustrates the underlying theoretical frameworks in this study.

3.1. Estimation of Bilateral Exposure Matrix. In this section, we introduce the methodology used in [19] for estimating the bilateral exposure matrix of banking system. The interbank exposures cannot be fully observed due to the fact that some bank's information is not transparent; therefore, we estimate the interbank bilateral exposure matrix by minimizing the uncertainty of bank's lending information based on the initial total interbank assets data $a_{i}$ and total interbank liabilities data $b_{i}$ in the balance sheet. The lending relationship in 


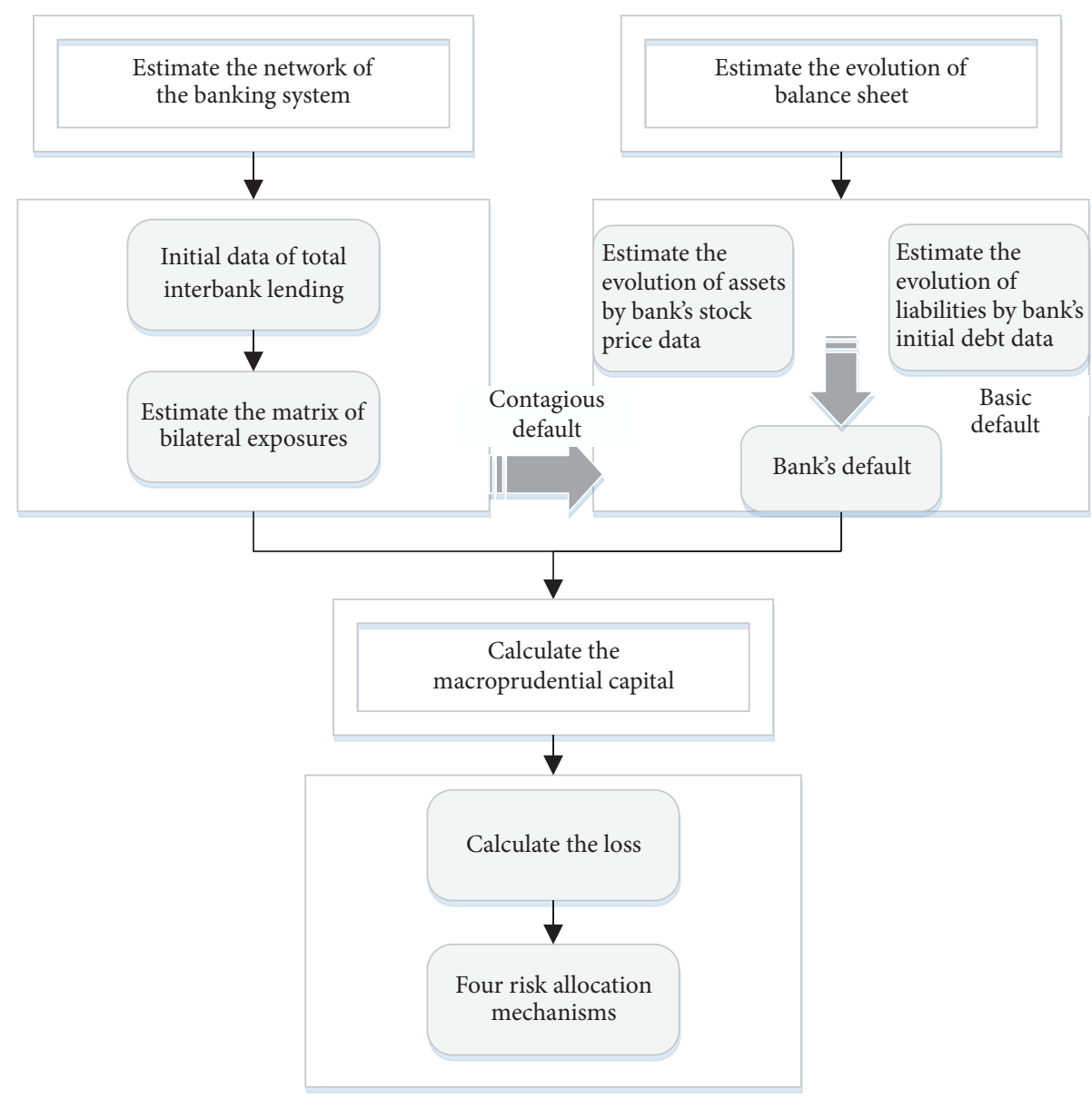

Figure 1: The theoretical framework.

the interbank market is represented by $(N \times N)$ nominal interbank matrix $X$ :

$$
X=\left[\begin{array}{cccccc}
x_{11} & \ldots & x_{1 j} & \ldots & x_{1 N} \\
\vdots & \ddots & \vdots & \ddots & \vdots \\
\sum_{i} & \ldots & x_{i j} & \ldots & x_{i N} \\
x_{i 1} & \ddots & \vdots & \ddots & \vdots \\
\vdots & \ldots & b_{1} & b_{i} \\
x_{N 1} & & x_{N j} & \ldots & x_{N N}
\end{array}\right] b_{N}
$$

where $x_{i j}$ represents the outstanding loans of bank $i$ to bank $j$, the sum of each row $b_{i}$ represents the total interbank liability of bank $i$, and the sum of each column $a_{j}$ represents the total interbank assets of bank $j$. It is donated as

$$
\begin{gathered}
b_{i}=\sum_{j} x_{i j}, \\
a_{j}=\sum_{i} x_{i j} .
\end{gathered}
$$

We minimize the uncertainty of bank's lending information by standardizing $\sum_{j} a_{j}=\sum_{i} b_{i}=1$, to get the results $x_{i j}=$ $a_{j} * b_{i}$, which represents the standardized lending relationship of bank $i$ to bank $j$. We know that the diagonal elements of $X$ have to be zero; thus we make new definitions for the elements $x_{i j}$ in the interbank matrix $X$ as follows:

$$
x_{i j}^{0}= \begin{cases}0, & i=j, \\ a_{j} b_{i}, & \text { otherwise }\end{cases}
$$

However, $X^{0}=\left(x_{i j}^{0}\right)$ violates the summing constraints expressed in (2). The standard way in the literature to handle this problem is to optimize the elements in the interbank matrix according to (4):

$$
\begin{array}{r}
\min \sum_{i=1}^{N} \sum_{j=1}^{N} x_{i j} \ln \left(\frac{x_{i j}}{x_{i j}^{0}}\right) \\
\sum_{j=1}^{N} x_{i j}=b_{i}, \sum_{i=1}^{N} x_{i j}=a_{j}, x_{i j} \geq 0 .
\end{array}
$$




\subsubsection{The Algorithm of Estimating the Bilateral Exposures Matrix}

Step 1. Start the iteration for the elements in the interbank matrix $X, x_{i j}^{0}=a_{j} b_{i}$ if $i \neq j$; otherwise $x_{i j}^{0}=0$.

Step 2. Take the rows constraint and set

$$
x_{i j}^{1}=\frac{x_{i j}^{0} b_{i}}{\sum_{i=1}^{N} \sum_{j=1}^{N}\left(b_{i} * a_{j}\right)}, \quad i \in 1,2, \ldots, N
$$

Step 3. Take the columns constraint and set

$$
x_{i j}^{2}=\frac{x_{i j}^{1} a_{j}}{\sum_{i=1}^{N} \sum_{j=1}^{N}\left(b_{i} * a_{j}\right)}, \quad j \in 1,2, \ldots, N .
$$

The $K$ iteration runs across the rows and columns constraints show that

$$
\begin{gathered}
x_{i j}^{K}=\frac{x_{i j}^{K-1} b_{i}}{\sum_{i=1}^{N} \sum_{j=1}^{N}\left(b_{i} * a_{j}\right)}, \quad i \in 1,2, \ldots, N, \\
x_{i j}^{K+1}=\frac{x_{i j}^{K} a_{j}}{\sum_{i=1}^{N} \sum_{j=1}^{N}\left(b_{i} * a_{j}\right)}, \quad j \in 1,2, \ldots, N .
\end{gathered}
$$

The iteration is stopped when $x_{i j}^{K+1}-x_{i j}^{K-1}<\varepsilon$, where $\varepsilon>0$.

3.2. Estimation of the Time Evolution of $V_{i}$. The asset value of bank is not daily observable, but we can obtain the data at the end of year from the balance sheet. The daily data of equity prices can be collected from the stock market on daily basis. Following Merton [35] we interpret equity as a call option on bank assets; thus we can estimate the time evolution of asset value by the stochastic model and maximum likelihood function based on the time series data of bank's equity prices. We assume that the asset value $V_{i}$ of bank $i$ follows a geometric Brownian motion with drift $u_{i}$ and volatility $\sigma_{i}$ :

$$
d V_{i}=u_{i} V_{i} d t+\sigma_{i} V_{i} d_{Z}
$$

The equity value of bank $i S_{t}(t)$ is given by the Black-Scholes model as follows:

$$
S_{t}(t)=V_{i}(t) \phi\left(d_{t}\right)-D_{i}(t) \phi\left(d_{t}-\sigma_{i} \sqrt{T}\right)
$$

Then equity $S_{t}(t)$ can be seen as a call option on the assets of bank $i$ with a strike price equal to the future notional value of bank $i$ 's debt $D_{i}(t)$, which is assumed to have a maturity of $T . \phi(\bullet)$ is the standard normal distribution function, $T=365$ days, $t$ represents the evolution of days, and

$$
d_{t}=\frac{\ln \left(V_{i}(t) / D_{i}(t)\right)+\left((1 / 2) \sigma_{i}^{2}\right) T}{\sigma_{i} \sqrt{T}} .
$$

By using the time series of equity prices $\left\{S_{i}(0)\right.$, $\left.S_{i}(1), \ldots, S_{i}(T)\right\}$ from the stock market, the face value of total liabilities $\left\{D_{i}(0), D_{i}(1), \ldots, D_{i}(T)\right\}$, where $D_{i}(t)=D_{i}(0) e^{r t}$ from the balance sheet, the arbitrary initial value of $\mu_{i}(0)$, $\sigma_{i}(0)$, and the risk-free rate $r$ that is obtained from the Central bank of Nigeria from 2008 to 2014, we can estimate the time series of assets value $\left\{\widehat{V}_{i}(1), \widehat{V}_{i}(2), \ldots, \widehat{V}_{i}(T)\right\}$ according to (9). Then we use the following maximization likelihood function to estimate the parameters $\widehat{u}_{i}$ and $\widehat{\sigma}_{i}$ :

$$
\begin{aligned}
L\left(\widehat{u}_{i}, \widehat{\sigma}_{i} ; \widehat{V}_{i}(1), \widehat{V}_{i}(2), \ldots, \widehat{V}_{i}(T)\right) \\
=-\frac{T}{2} \ln \left(2 \pi \sigma_{i}^{2} h\right)-\frac{T}{2} \sum_{k=1}^{T} \frac{\left(R_{i}(k)-\left(u_{i}-\sigma_{i}^{2} / 2\right) h\right)^{2}}{\sigma_{i}^{2} h} \\
\quad-\sum_{k=1}^{T} \ln \widehat{V}_{k},
\end{aligned}
$$

where $R_{i}(k)=\ln \left(\widehat{V}_{i}(t) / \widehat{V}_{i}(t-1)\right), h=1 / 365$. In this case $h$ represents business days instead of calendar days. According to the stock market data source, $h$ may equal about 250 , which will be different at each year.

The estimated parameters are denoted as $\widehat{u}_{i}, \widehat{\sigma}_{i}$ respectively. We compare the estimated parameters $\widehat{u}_{i}, \widehat{\sigma}_{i}$ with the initial value $u_{i}(0), \sigma_{i}(0)$; if $\widehat{u}_{i}, \widehat{\sigma}_{i}$ do not equal to $u_{i}(0), \sigma_{i}(0)$; we replace the initial value $u_{i}(0), \sigma_{i}(0), V_{i}(0)$ with $\hat{u}_{i}, \widehat{\sigma}_{i}, \bar{V}_{i}(0)$ and then repeat the estimation method from (9), (10), and (11) once again until the estimated parameters $\widehat{u}_{i}, \widehat{\sigma}_{i}$ equal to $u_{i}(0)$, $\sigma_{i}(0)$. Accordingly we get the estimated parameters $u_{i}$ and $\sigma_{i}$. Then according to (12), we get the evolution of $V_{i}(t)$.

$$
V_{i}(t)=V_{i}(0) e^{u_{i}-\left(\sigma_{i}^{2} / 2\right) t h+\sigma_{i} \sqrt{t h * z_{i}(t)}},
$$

where $z_{i}(t)$ obeys normal distribution $(N(0,1))$.

The above estimation method of $V_{i}(t)$ is the same as [6].

To test the stability of the bank network system, we add a system shock to the bank system. If the banks withstand a strong shock, then we say that the system is stable. If the bank system collapses when a weak shock applies, then we say that the bank system is unstable. Thus, we apply a medium shock to count the number of banks which undergoes bankruptcy. If the probabilities of the banks which undergo bankruptcy are large for a medium shock, then the bank system is unstable. The system shock is added to the banking system by replacing $z_{i}(t)$ in $(12)$ with $(1-\xi) z_{i}(t)+\xi * \omega(t)$ where $\xi$ represents the strength of the system shock and $\omega(t)$ is the system shock which is the same for all banks. $\omega(t)$ follows the normal distribution $(N(0,1))$, where $\xi=0.1$. Thus the evolution of $V_{i}(t)$ can be estimated as follows:

$$
V_{i}(t)=V_{i}(0) e^{u_{i}-\left(\sigma_{i}^{2} / 2\right) t h+\sigma_{i} \sqrt{t h *\left[(1-\xi) z_{i}(t)+\xi * \omega(t)\right]}} .
$$

3.3. The Measures of Banks Defaults. In the present paper, we consider the risk of bank defaults that are basic defaults and contagious defaults. When bank $i$ is insolvent, we define it as the basic default which satisfied

$$
V_{i}(t)-D_{i}(t)<0,
$$


where $D_{i}(t)$ can be described as follows:

$$
D_{i}(t)=\left(V_{i}(0)-C_{i}(0)\right) e^{r t}
$$

In (15), $r$ is risk-free rate. We set $C_{i}(0)=7 \% * V_{i}(0)$, namely, $\left(V_{i}(0)-D_{i}(0)\right) / V_{i}(0)=7 \%$, where $D_{i}(0)=V_{i}(0)-C_{i}(0)$. The $7 \%$ is a capital adequacy ratio according to Basel III; therefore $C_{i}(0)$ is the initial capital of bank $i$.

If bank $i$ satisfies (14), bank $i$ occurs as basic default. The losses come from $V_{i}(t)-D_{i}(t)$. Due to the variable $V_{i}(t)$ following random walk, it will fluctuate around the drift $u_{i}$; however, $D_{i}(t)$ is a variable that is increasing with time. Therefore, with the time step increasing, there must be some banks default. Then through the interbank market, bank $i$ may cause the other banks default, which is the contagion default. Here, we extend the clearing payment mechanism [11] to suit the calculation of the time evolution of the contagion default. We define a new matrix $\Pi \in[0,1]^{N \times N}$ to standardize the total interbank liabilities:

$$
\Pi_{i j}(t)= \begin{cases}\frac{x_{i j}(t)}{b_{i}(t)} & b_{i}(t)>0 \\ 0 & \text { otherwise }\end{cases}
$$

where $b_{i}(t)=\sum_{j} x_{i j}(t)$; this shows the total interbank liabilities of bank $i$ at time step $t$. We also define a clearing payment vector $p^{*}(t)$ that respects the limited liability of banks and proportional sharing in case of default. It denotes the total payments made by the banks under the clearing mechanism defined as

$$
p_{i}^{*}(t)=\left\{\begin{array}{l}
b_{i}(t) \\
\sum_{j=1}^{N} \Pi_{j i}(t) p_{j}^{*}(t)+e_{i}(t) \\
0
\end{array}\right.
$$

where $e_{i}(t)=V_{i}(t)-D_{i}(t)$. Here, we adopt the default algorithm [11] to find a clearing payment vector. If bank $i$ cannot default according to (14), it may default when other banks are not able to keep their promises; that is, contagious default of bank $i$ occurs if

$$
\sum_{j=1}^{N} \Pi_{j i}(t) p_{j}^{*}(t)+e_{i}(t)-b_{i}(t)<0 .
$$

3.3.1. The Evolution of the Bilateral Exposures $X(t+1), a_{j}(t+1)$, and $b_{i}(t+1)$. After calculating a clearing payment vector at time step $t$, we can calculate the new matrix of $X$ at the time step $t+1$. We should note that when bank $i$ defaults, bank $i$ can pay only a part of its liabilities to other banks. The ratio is defined as follows:

$$
\chi_{i}=\frac{\sum_{j=1}^{N} \Pi_{i j}^{\prime}(t) p_{j}^{*}(t)+e_{i}(t)}{b_{i}(t)} .
$$

The total assets and liabilities of bank $j$ from time step $t+1$ to $T$ will be updated as follows:

$$
\begin{aligned}
& V_{j}(t+1: T)=V_{j}(t)-x_{j i} \\
& D_{j}(t+1: T)=D_{j}(t)-x_{j i} \\
& V_{j}(t+1: T)=V_{j}(t)-\left(1-\chi_{i}\right) x_{i j} .
\end{aligned}
$$

When bank $i$ defaults, we set $x_{i, j}(t)=0, x_{j, i}(t)=0$ and clear out bank $i$ from the network bank system. Then, we need to recalculate the bilateral exposures matrix $X_{t+1}$ according to

$$
\begin{aligned}
& \sum_{j=1}^{N} \Pi_{j i}(t) p_{j}^{*}(t)+e_{i}(t) \geq b_{i}(t), \\
& 0 \leq \sum_{j=1}^{N} \Pi_{j i}(t) p_{j}^{*}(t)+e_{i}(t)<b_{i}(t), \\
& \sum_{j=1}^{N} \Pi_{j i}(t) p_{j}^{*}(t)+e_{i}(t)<0,
\end{aligned}
$$

the algorithm in Section 3.1.1. Thus, the evolution of $a_{j}(t+1)$ and $b_{i}(t+1)$ is described as

$$
\begin{aligned}
& a_{j}(t+1)=\sum_{i=1}^{N} x_{i, j}(t+1) \\
& b_{i}(t+1)=\sum_{j=1}^{N} x_{i, j}(t+1) .
\end{aligned}
$$

Thus, we measure the stability of the banking system by calculating the probability of bank's default. The probability of basic default of bank $i$ is calculated as the ratio of the times of basic default of bank $i$ occurring and the total times of the simulation. Similarly, the probability of the contagious default of bank $i$ is calculated as the ratio of the times of contagious default of bank $i$ occurring and the total times of the simulation. The probability of the total default of banking system is the sum of the basic defaults probability and contagious defaults probability.

3.4. The Measure of Bank's Macroprudential Capital. The core algorithm of calculating bank's macroprudential capital lies in measuring bank's losses, which is defined as

$$
l_{i}(t)=\min \left(\sum_{j=1}^{N} \Pi_{j i}(t) p_{j}^{*}(t)+e_{i}(t)-b_{i}(t), 0\right) .
$$

The dynamic evolution (time step $t$ ) of banking system is iterated for test of times (test $=1,2,3, \ldots, M) ; l_{i \text {,test }}(t)$ represents the loss of bank $i$ at every time of simulation. 


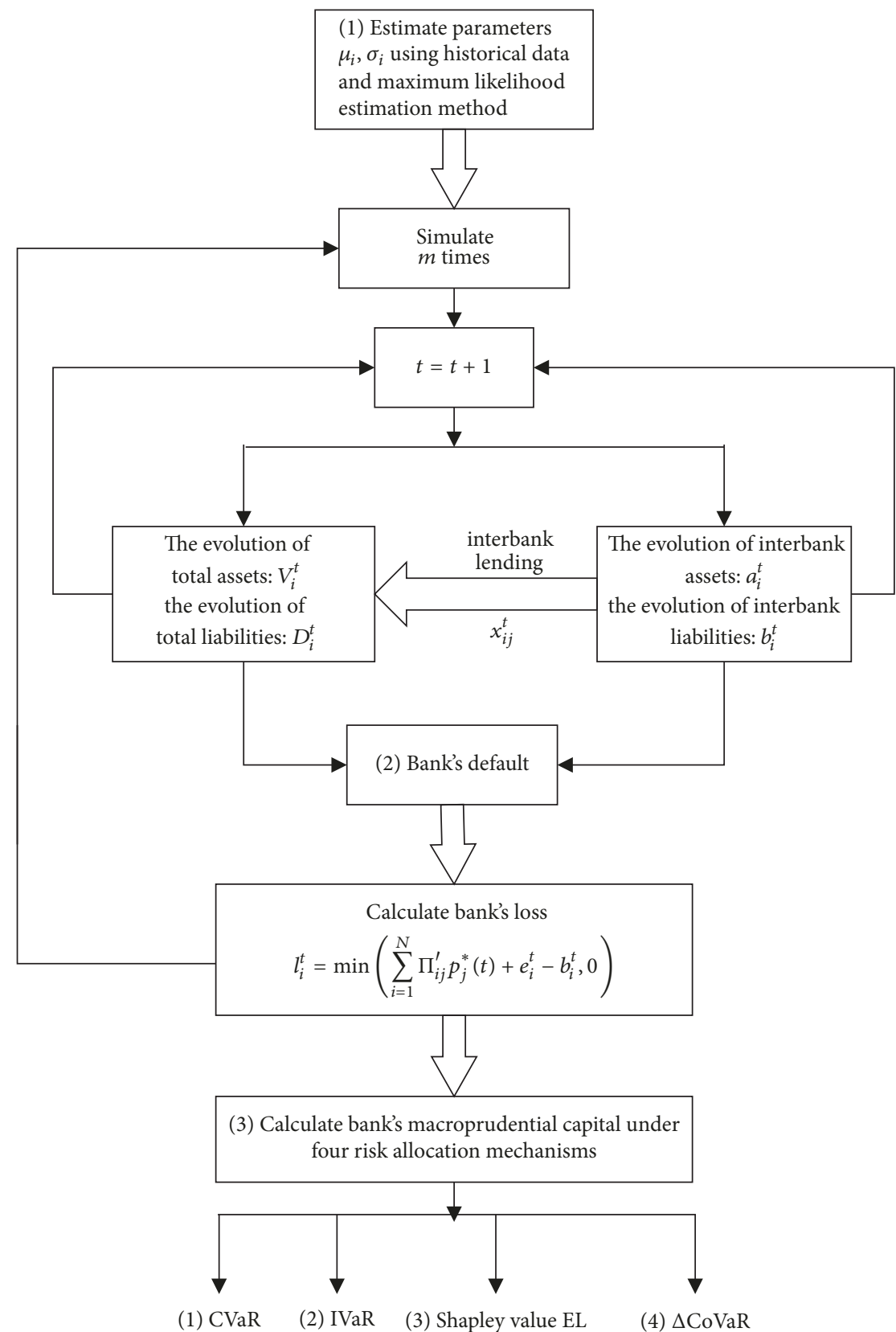

Figure 2: The algorithm flowchart of calculating macroprudential capital requirements.

Therefore, we get a $N \times M$ loss matrix of $N$ banks in $M$ times of simulation. The loss matrix under the given capital $C_{i}=\left(C_{1}, C_{2}, \ldots, C_{N}\right)$ can be expressed as $l(C)$; then, we use the risk allocation mechanism $f(\bullet)$ to allocate systemic risk to every bank, which is described as $f_{i}(l(C))$. Thus, the macroprudential capital of bank $i$ is computed as

$$
\begin{aligned}
C_{i}^{*} & =f_{i}\left(l\left(C_{i}^{*}\right)\right) \times\left(\sum_{i=1}^{N} C_{i}^{0}\right) \\
\sum_{i=1}^{N} f_{i}(l(C)) & =1, \quad f_{i}(l(C)) \geq 0,
\end{aligned}
$$

where $C_{i}^{0}$ is the initial capital of bank $i ; C_{i}^{*}$ is the redistributed capital of bank $i$. The algorithm flowchart of calculating bank's macroprudential capital is shown in Figure 2.

\section{Macroprudential Capital Measures Underlying Four Risk Allocation Mechanisms}

Following Caccioli et al. [24] and Liao et al. [36], we use four risk allocation mechanisms to calculate each bank's macroprudential capital requirements, namely, Component VaR, Incremental VaR, Shapley value, and $\Delta \mathrm{CoVaR}$. The methods 
for calculating bank's macroprudential capital requirements are summarized as follows.

4.1. Component VaR. The core of this allocation mechanism is to reallocate the capital based on the contribution $\beta$ of each bank's loss $l_{i}$ to the total loss of banking system $\sum_{i=1}^{n} l_{i}\left(l_{p}\right)$, and $\beta_{i}=\operatorname{cov}\left(l_{i}, l_{p}\right) / \sigma^{2}\left(l_{p}\right)$. The macroprudential capital of bank $i$ under the Component VaR mechanism is given by

$$
C_{i}^{\mathrm{CVaR}}=\beta_{i} \sum_{i=1}^{n} C_{i}^{0}
$$

The change in capital under the Component VaR mechanism is $\left(C_{i}^{\mathrm{CVaR}}-C_{i}^{0}\right) / C_{i}^{0}$.

4.2. Incremental VaR. The theme of this allocation procedure is to reallocate the capital according to the change in the overall risk due to the exclusion of a bank in the system.

Individual bank losses are simulated over ten thousand scenarios and for each scenario we compute the $5 \% \mathrm{VaR}$ of the total losses $l_{p}$ in the system, denoted by $\mathrm{VaR}_{P}$. Then, we calculate the $5 \%$ VaR of total losses excluding bank $i$ denoted by $\mathrm{VaR}^{-i}$. Thus, the increment $\mathrm{VaR}$ of bank $i$ is calculated as

$$
\mathrm{IVaR}_{i}=\mathrm{VaR}_{P}-\mathrm{VaR}^{-i}
$$

The macroprudential capital of bank $i$ under the increment VaR mechanism is given by

$$
C_{i}^{\mathrm{IVaR}}=\frac{\mathrm{IVaR}_{i}}{\sum_{i=1}^{n} \mathrm{IVaR}_{i}} \sum_{i=1}^{n} C_{i}^{0} .
$$

The change in capital under the increment VaR mechanism is $\left(C_{i}^{\mathrm{IVaR}}-C_{i}^{0}\right) / C_{i}^{0}$.

4.3. Shapley Value EL. The Shapley value EL method is the arithmetic average of $n$ times of simulation based on the increment VaR mechanism. Thus, a new $\mathrm{IVaR}_{i}$ is represented as $\phi_{i}$ by the calculation of arithmetic average based on $\operatorname{VaR}_{P}$ and $\mathrm{VaR}^{-i}$.

Thus we compute the macroprudential capital requirements of bank $i$ under the Shapley value EL mechanism by

$$
C_{i}^{\text {Shapley EL }}=\frac{\phi_{i}}{\sum_{i=1}^{n} \phi_{i}} \sum_{i=1}^{n} C_{i}^{0} .
$$

The change in capital under the Shapley value EL mechanism is $\left(C_{i}^{\text {Shapley EL }}-C_{i}^{0}\right) / C_{i}^{0}$.

4.4. $\triangle$ CoVaR. We define CoVaR of bank $i$ as the total loss of banking system conditional on bank $i$ realizing a loss corresponding to its $\mathrm{VaR}$. CoVaR $i$ is described as

$$
\begin{aligned}
& \operatorname{Pr}\left(l_{p}<\mathrm{CoVaR}_{i} \mid l_{i} \in\left[(1-\ell) \operatorname{VaR}_{i},(1+\ell) \operatorname{VaR}_{i}\right]\right) \\
& \quad=0.5 \%, \quad \ell=0.1 .
\end{aligned}
$$

Here $\Delta \mathrm{CoVaR}_{i}$ is defined as the difference of $\mathrm{CoVaR}_{i}$ and the $\mathrm{VaR}$ of the total losses in the banking system conditional on bank $i$ making a loss at its median:

$$
\Delta \mathrm{CoVaR}_{i}=\mathrm{CoVaR}_{i}-\left(\operatorname{VaR}_{p} \mid l_{i}=\operatorname{median}\left(l_{i}\right)\right) .
$$

The macroprudential capital of bank $i$ under the $\Delta$ CoVaR mechanism is given by

$$
C_{i}^{\Delta \mathrm{CoVaR}}=\frac{\Delta \mathrm{CoVaR}_{i}}{\sum_{i=1}^{n} \Delta \mathrm{CoVaR}_{i}} \sum_{i=1}^{n} C_{i}^{0} .
$$

The change in capital under the $\triangle \mathrm{CoVaR}$ mechanism is $\left(C_{i}^{\Delta \mathrm{CoVaR}}-C_{i}^{0}\right) / C_{i}^{0}$.

\section{Data}

In this paper, we use financial data collected from the African markets website. The study involves 10 major public traded commercial banks in Nigeria from 2008 to 2014. The sample of 10 banks is selected based on banks with large assets value, namely, Zenith International bank ( 3.3 trillion), FBN Holdings ( 3.2 trillion), Guaranty bank ( 3.15 trillion), United bank of Africa ( 2 trillion), Diamond bank ( 1.93 trillion), Access bank ( 1.835 trillion), Fidelity ( 1.19 trillion), Union bank of Nigeria ( 1.049 trillion), Skye bank (1 trillion), and Sterling bank ( 841 billion) as of 2015 (https://www.relbanks.com).

\section{Results}

6.1. Changes in Capital Requirements. In this section we present the changes in capital requirements to reach the fixed point of the four capital allocation mechanism presented in Section 4 in percent of actual observed capital requirements. We use numbers 1, 2, 3, 4, 5, 6, 7, 8, 9, and 10 to portray Access bank, Diamond bank, FBNH, Fidelity bank, Guaranty bank, Skye bank, Sterling bank, Union bank of Nigeria, United bank of Africa, and Zenith International bank, respectively. We use different risk allocation mechanisms to reallocate the current capital in the system as shown in Section 4. Reallocation of capital in the system through new capital requirements changes a banks probability of default and systemic risk. In the first scenario, we assume the case where the system shocks do not exist in the system for the period of 2008-2009.

Table 1 presents the increase in capital as a share of these banks' risk weighted assets from the current observed capital level $C_{i}^{0}$ to macroprudential capital requirement $C_{i}^{*}$. The change is presented as a proportion of current observed capital level $C_{i}^{0}$; for example, $\left(C_{i}^{*}-C_{i}^{0}\right) / C_{i}^{0}$.

The methods of four risk allocation mechanisms are quite different from each other. Since Shapley value is based on incremental VaR, in Table 1, these two results are similar. The method of the Component VaR calculates the correlation between each bank's losses and the total loss of banking system. In Table 1, it seems the losses of bank 10 are not very related to other 9 banks. The method of $\triangle \mathrm{CoVaR}$ is related to the total loss of banking system conditional on bank $i$ 
TABLE 1: Increase in capital as a share of banks' risk weighted assets for macroprudential capital allocation mechanism in 2008.

\begin{tabular}{lcccc}
\hline Bank & Component VaR & Incremental VaR & Shapley value EL & $\Delta$ COVAR \\
\hline 1 & -0.224490152 & 0.075807121 & 0.079291353 & -0.53067966 \\
2 & -0.224490152 & -0.098024516 & -0.108952535 & 1.278613545 \\
3 & -0.224490152 & -0.093480509 & -0.097516656 & -0.413673209 \\
4 & -0.224490152 & -0.162273193 & -0.164247199 & 0.181725936 \\
5 & -0.224490152 & -0.144122078 & -0.144675929 & 1.185156475 \\
6 & -0.224490152 & 0.129450668 & 0.130866402 & 1.171263759 \\
7 & -0.224490152 & -0.052641093 & -0.050383221 & 1.862680122 \\
8 & -0.224490152 & 0.739933973 & 0.74625635 & -0.329806275 \\
9 & 1.205658115 & -0.144056852 & -0.144084074 & -0.507137053 \\
10 & -0.224490152 & -0.151642289 & -0.151117088 & -0.631962395 \\
\hline
\end{tabular}

TABLE 2: Increase in capital as a share of banks' risk weighted assets for macroprudential capital allocation mechanisms in 2009.

\begin{tabular}{lcccc}
\hline Bank & Component VaR & Incremental VaR & Shapley value EL & $\Delta$ COVAR \\
\hline 1 & -0.838983488 & -0.321911 & -0.277249974 & 0.339348356 \\
2 & -0.838983488 & -0.324542322 & -0.291759584 & 0.492986513 \\
3 & -0.838983488 & 0.037474798 & 0.026574758 & -0.49003279 \\
4 & -0.838983488 & -0.392470575 & -0.377802565 & 0.792001406 \\
5 & -0.838983488 & -0.318295374 & -0.313198791 & -0.10427448 \\
6 & -0.838983488 & -0.324506098 & -0.3050429 & 0.453956728 \\
7 & -0.838983488 & -0.367389192 & -0.345570211 & 3.392491614 \\
8 & -0.838983488 & 0.735790757 & 0.738495391 & -0.18476422 \\
9 & -0.838983488 & 0.565740871 & 0.550344543 & -0.0511749 \\
10 & 4.219043349 & -0.292376022 & -0.31859484 & -0.41648809 \\
\hline
\end{tabular}

realizing a loss corresponding to its $\mathrm{VaR}$, and the method is more related to the median of each bank's losses; therefore, it may eliminate the effect of extreme value. Therefore, the results of $\Delta \mathrm{CoVaR}$ for ten banks in Table 1 seem more uniform than the method of Component VaR.

All risk allocation rules suggest that banks 3 and 10 hold more capital than their contribution to the overall risk the system would require. The results are mixed for both banks, under three out of four capital allocations mechanisms suggesting that banks 2, 4, 5, 7, and 9 hold more capital for unexpected losses while bank 6 holds little capital. For bank 1 and 8 the results shows that two out of four capital allocation mechanisms suggest that the bank holds little; the remaining holds more capital.

In Table 2, all risk allocation rules suggest that bank 5 holds more capital than its contribution to the overall risk the system would require. Three out of four capital allocations mechanisms suggest that banks $1,2,4,6,7$, and 10 hold more capital. For banks 3, 8, and 9 the results show that two out of four capital allocation mechanisms suggest that the bank holds little, the remaining holds more capital.

We also examine the changes in the capital requirements when the system shock exists in the system for the period 2008-2014. We use the same risk allocation mechanism to compute the current capital in the system. Our results are presented in Figure 3. Figure 3 portrays the changes of capital expressed in percentage according to macroprudential capital requirements in situation where the system shock exists in Nigerian banking system. We note that almost all risk allocation rules suggest that almost all banks appear to be undercapitalized because nearly all the changes are positive.

6.2. Probability of Bank Defaults and Macroprudential Capital Requirements. Macroprudential capital requirements can serve as buffers against the risk created in the banking system. To supplement our findings which are the core elements of our study, we thus examine the extent in which macroprudential capital requirements reduce the average bank default probability compared to the probability under Basel equal. We use different risk allocation mechanisms to show the individual bank default probabilities. Table 3 depicts the differences in macroprudential capital requirements under different risk mechanisms; almost all these allocations reduce default probabilities compared to the benchmarks "Basel equal approach."

Table 3 depicts the individual bank default probabilities under the Basel equal and macroprudential capital requirements computed with four systemic risk allocation mechanisms expressed in percent. Average shows the average default probability. The table depicts that Skye bank, Guaranty bank, and Diamond bank are bit weaker banks in the system as they have the highest total probabilities of basic and contagious default as shown in Table 5; overall total default probabilities range between $0.0081 \%$ and $0.1422 \%$.

In addition, the findings show that capital requirements under $\triangle$ COVAR lead to the lowest default probability. The 

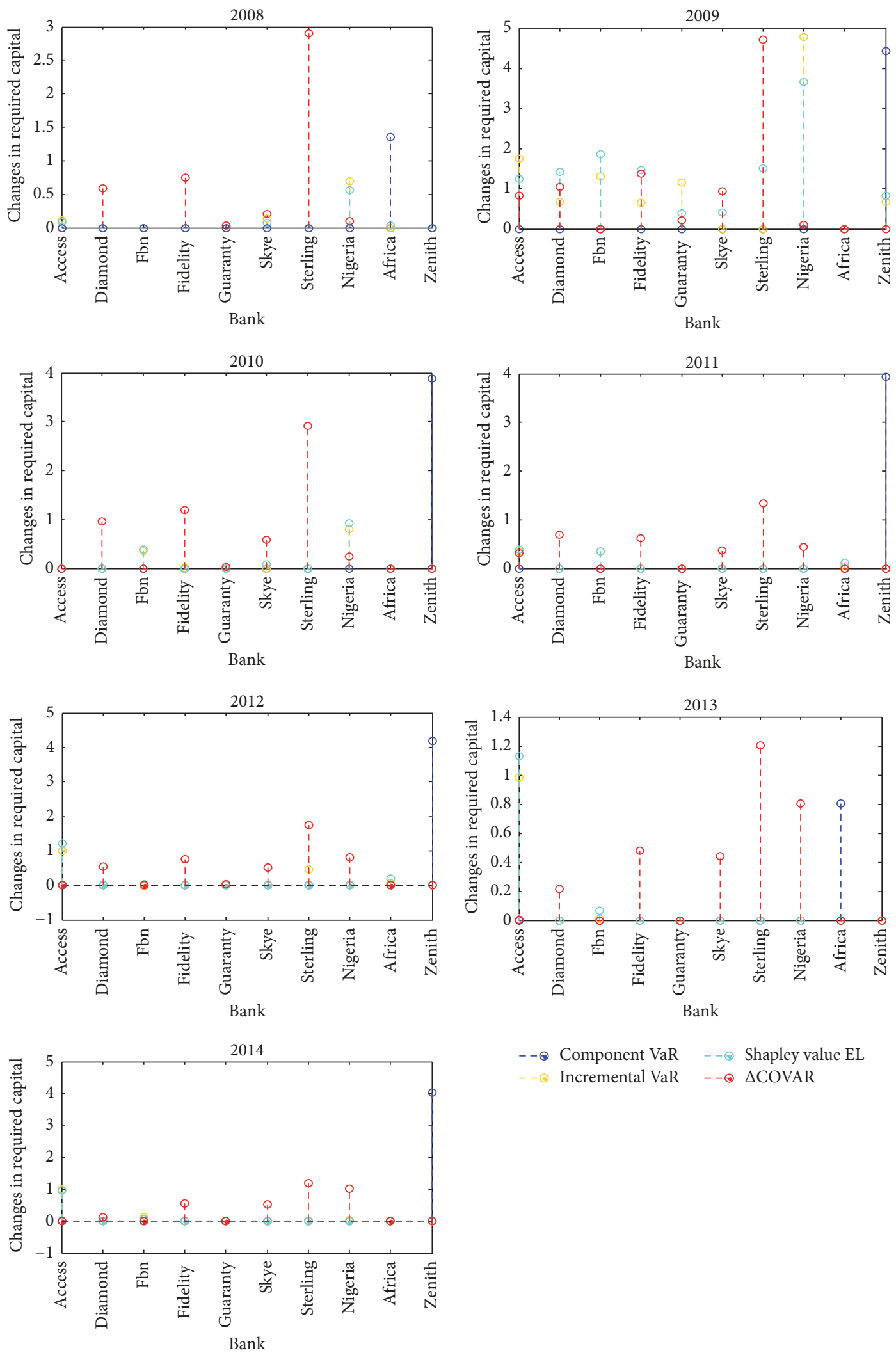

- Incremental VaR - $-\odot \Delta$ COVAR

$--\odot$ Component VaR $--\odot$ Shapley value EL

(-) Incremental VaR $--\infty \Delta \mathrm{COVAR}$

FIGURE 3: Increase in capital as a share of banks' risk weighted assets using four risk allocation mechanisms assuming shocks exist. 
TABLE 3: Individual bank default probabilities under the macroprudential capital requirements in 2008.

\begin{tabular}{|c|c|c|c|c|c|}
\hline Bank & Basel equal & Component VaR & Incremental VaR & Shapley value EL & $\triangle \mathrm{COVAR}$ \\
\hline 1 & 0.0552 & 0.0552 & 0.0332 & 0.0405 & 0.0552 \\
\hline 2 & 0.1344 & 0.1344 & 0.1344 & 0.1344 & 0.0238 \\
\hline 3 & 0.0952 & 0.0952 & 0.0952 & 0.0952 & 0.0952 \\
\hline 4 & 0.0787 & 0.0787 & 0.0787 & 0.0787 & 0.0033 \\
\hline 5 & 0.1356 & 0.1356 & 0.1356 & 0.1356 & 0.1268 \\
\hline 6 & 0.1422 & 0.1422 & 0.0991 & 0.1201 & 0.0845 \\
\hline 7 & 0.1247 & 0.1247 & 0.1247 & 0.1247 & 0 \\
\hline 8 & 0.0081 & 0.0081 & 0 & 0.0001 & 0.0032 \\
\hline 9 & 0.1065 & 0.0002 & 0.1065 & 0.0986 & 0.1065 \\
\hline 10 & 0.0511 & 0.0511 & 0.0511 & 0.0511 & 0.0511 \\
\hline Average & 0.09317 & 0.08254 & 0.08585 & 0.0879 & 0.05496 \\
\hline
\end{tabular}

TABLE 4: Individual bank default probabilities under the macroprudential capital requirements in 2009.

\begin{tabular}{lccccc}
\hline Bank & Basel equal & Component VaR & Incremental VaR & Shapley value EL & $\Delta$ COVAR \\
\hline 1 & 0.1177 & 0.1177 & 0 & 0.0006 & 0.0065 \\
2 & 0.1311 & 0.1311 & 0.0111 & 0.0001 & 0 \\
3 & 0.1 & 0.1 & 0 & 0.0018 \\
4 & 0.1508 & 0.1508 & 0.0197 & 0.0005 & 0.0558 \\
5 & 0.157 & 0.157 & 0.0023 & 0.0543 & 0.0752 \\
6 & 0.1643 & 0.1643 & 0.1643 & 0.0002 & 0 \\
7 & 0.18 & 0.18 & 0.18 & 0.0063 \\
8 & 0.0722 & 0.0722 & 0 & 0.9982 & 0.0263 \\
9 & 0.9982 & 0.9982 & 0.9982 & 0.0037 \\
10 & 0.1222 & 0.0886 & 0.0094 & 0.11134 \\
\hline
\end{tabular}

average probability of bank defaults based on $\triangle$ COVAR decreases from $0.09317 \%$ to $0.05496 \%$, a $0.4101 \%$ reduction in risk. This proves that increased capital levels downsize default risk and thus macroprudential capital requirements serve as a buffer against internally created risk in the banking system. More importantly, other measures like Component VaR, Shapley value, and incremental value at risk also decrease individual bank default probabilities.

Table 4 portrays that United bank of Africa is a weaker bank in the system; overall total probabilities range between $0.1 \%$ and $0.9982 \%$. Moreover, the findings show that capital requirements under Shapley value lead to the lowest default probability. The average probability of bank defaults based on Shapley value decreases from $0.21935 \%$ to $0.11134 \%$, a $0.4924 \%$ reduction in risk; other measures like Component $\mathrm{VaR}$, incremental value at risk and $\triangle \mathrm{COVAR}$ also decrease individual bank default probabilities.

Figure 4 portrays individual bank total default probabilities under macroprudential capital requirements for the entire sample of 2008-2014.

From Figure 4, we see that in 2010 Access Bank seems to be the weaker bank in the system. We find that the overall total default probabilities range between $0.0247 \%$ and $0.9501 \%$, with $\triangle$ COVAR leading to the lowest default probability. Moreover the average probability of bank defaults based on $\triangle$ COVAR decreases from $0.13716 \%$ to $0.110084 \%$, that is, a $0.1974 \%$ reduction in risk. Other measures also appear to decrease individual bank defaults.

For year 2011, Sterling and United bank of Africa are bit weaker banks in the system. The overall total probabilities in the system range between $0.0091 \%$ and $0.977 \%$. Our results reveal that capital requirements under $\triangle$ COVAR lead to the lowest default probability with the average probability of bank defaults based on this measure decreasing from $0.05885 \%$ to $0.022254 \%$, which is approximately a $0.62185 \%$ reduction in risk; other measures appear to decrease the individual bank default probabilities. Meanwhile for 2012 we note that Access bank is a weaker bank in the system; overall total probabilities bank defaults range between $0.0122 \%$ and $0.8829 \%$. The findings also unveil that capital requirement under $\triangle$ COVAR leads to the lowest default probability with the average probability of bank defaults decreasing from $0.1271 \%$ to $0.10012 \%$, a $0.21227 \%$ reduction in risk; other measures do the same.

For year 2013 it can be seen that the overall total probabilities of bank defaults range between $0.001 \%$ and $0.0473 \%$; at the same time the findings reveal that $\triangle$ COVAR lead to lowest default probability with the average probability of bank defaults decreasing from $0.02212 \%$ to $0.00703 \%$, which implies a reduction in risk by $0.6822 \%$. Sterling and 
TABLE 5: Probabilities of Basic and contagious default in 2008.

\begin{tabular}{|c|c|c|c|c|c|}
\hline Bank & Basel equal & Component VaR & Incremental VaR & Shapley value EL & $\triangle \mathrm{COVAR}$ \\
\hline \multicolumn{6}{|l|}{ Basic default probabilities } \\
\hline Access bank & 0.0546 & 0.0546 & 0.0329 & 0.0403 & 0.0546 \\
\hline Diamond bank & 0.1342 & 0.1342 & 0.1342 & 0.1342 & 0.0234 \\
\hline Fbn holdings & 0.0949 & 0.0949 & 0.0949 & 0.0949 & 0.0949 \\
\hline Fidelity bank & 0.0783 & 0.0783 & 0.0783 & 0.0783 & 0.0033 \\
\hline Guaranty bank & 0.1349 & 0.1349 & 0.1349 & 0.1349 & 0.1256 \\
\hline Skye bank & 0.1418 & 0.1418 & 0.0986 & 0.1198 & 0.0837 \\
\hline Sterling bank & 0.1247 & 0.1247 & 0.1247 & 0.1247 & 0 \\
\hline Union bank of Nigeria & 0.008 & 0.008 & 0 & 0.0001 & 0.0031 \\
\hline United bank of Africa & 0.1057 & 0.0002 & 0.1057 & 0.0982 & 0.1057 \\
\hline Zenith international bank & 0.0504 & 0.0504 & 0.0504 & 0.0504 & 0.0504 \\
\hline Average & 0.09275 & 0.0822 & 0.08546 & 0.08758 & 0.05447 \\
\hline \multicolumn{6}{|c|}{ Contagion default probabilities } \\
\hline Access bank & 0.0006 & 0.0006 & 0.0003 & 0.0002 & 0.0006 \\
\hline Diamond bank & 0.0002 & 0.0002 & 0.0002 & 0.0002 & 0.0004 \\
\hline Fbn holdings & 0.0003 & 0.0003 & 0.0003 & 0.0003 & 0.0003 \\
\hline Fidelity bank & 0.0004 & 0.0004 & 0.0004 & 0.0004 & 0 \\
\hline Guaranty bank & 0.0007 & 0.0007 & 0.0007 & 0.0007 & 0.0012 \\
\hline Skye bank & 0.0004 & 0.0004 & 0.0005 & 0.0003 & 0.0008 \\
\hline Sterling bank & 0 & 0 & 0 & 0 & 0 \\
\hline Union bank of Nigeria & 0.0001 & 0.0001 & 0 & 0 & 0.0001 \\
\hline United bank of Africa & 0.0008 & 0 & 0.0008 & 0.0004 & 0.0008 \\
\hline Zenith international bank & 0.0007 & 0.0007 & 0.0007 & 0.0007 & 0.0007 \\
\hline Average & 0.00042 & 0.00034 & 0.00039 & 0.00032 & 0.00049 \\
\hline
\end{tabular}

Union bank of Nigeria appear to be weaker banks in the system in this year. For 2014 our findings unfold that United bank of Africa is a weaker bank in the system; overall total probabilities of bank defaults range between $0.006 \%$ and $0.0747 \%$; moreover the capital requirements under $\triangle \mathrm{COVAR}$ lead to the lowest default probability. The average probability of bank defaults based on $\triangle$ COVAR decreases from $0.02731 \%$ to $0.01631 \%$, a $0.4028 \%$ reduction in risk. More importantly, other measures like Component VaR, incremental value at risk, and Shapley value also decrease individual bank default probabilities.

Generally we note that despite the heterogeneity in macroprudential capital requirements across risk allocation mechanisms, all risk allocation rules bring a substantial improvement in bank stability relative to the existing regulatory framework. Compared to the bench mark, all capital allocations mechanisms reduce the probability of banks defaults, the lowest probability being shown by $\triangle$ COVAR measures. Our findings prove that increased capital levels reduce default risk, in line with macroprudential capital requirements serving as insurance against the risk created within the financial system.

\section{Conclusion}

One of the major objectives of macroprudential policy is to internalize the risk within the banking system so as to enhance financial stability. We used the complex network theory to construct the network model of banking system, whereby each bank is regarded as a node and connected with others through the interbank bilateral exposures. We used different risk allocation mechanisms to reallocate the current capital in the system. We realized that the financial system risk, individual bank risk contribution, and bank default probability change upon the reallocation of capital in the system.

Thus we used a method to compute a fixed point for which capital redistribution is accordant with the contributions of each bank to the total risk of the banking system under proposed capital allocation mechanisms. Upon reallocation of capital in the system, we based on two scenarios; firstly in the situation where the system shocks do not exist in the system; in this scenario, we found that almost all banks appear to hold more capital. This ensures that banks build up capital during normal times so that it cannot be affected when losses are incurred during periods of financial difficulties. Secondly, we consider the situation where the system shock exists in the system; we found that almost all banks tend to hold little capital on both risk allocation mechanisms.

Our results show that United bank of Africa is the weakest in the system with high default probability in 2009, 2011, and 2014 followed by Access bank in 2010 and 2012; regulators should apply stringent supervision to these banks. We reveal that, under diverse risk allocation mechanisms, 

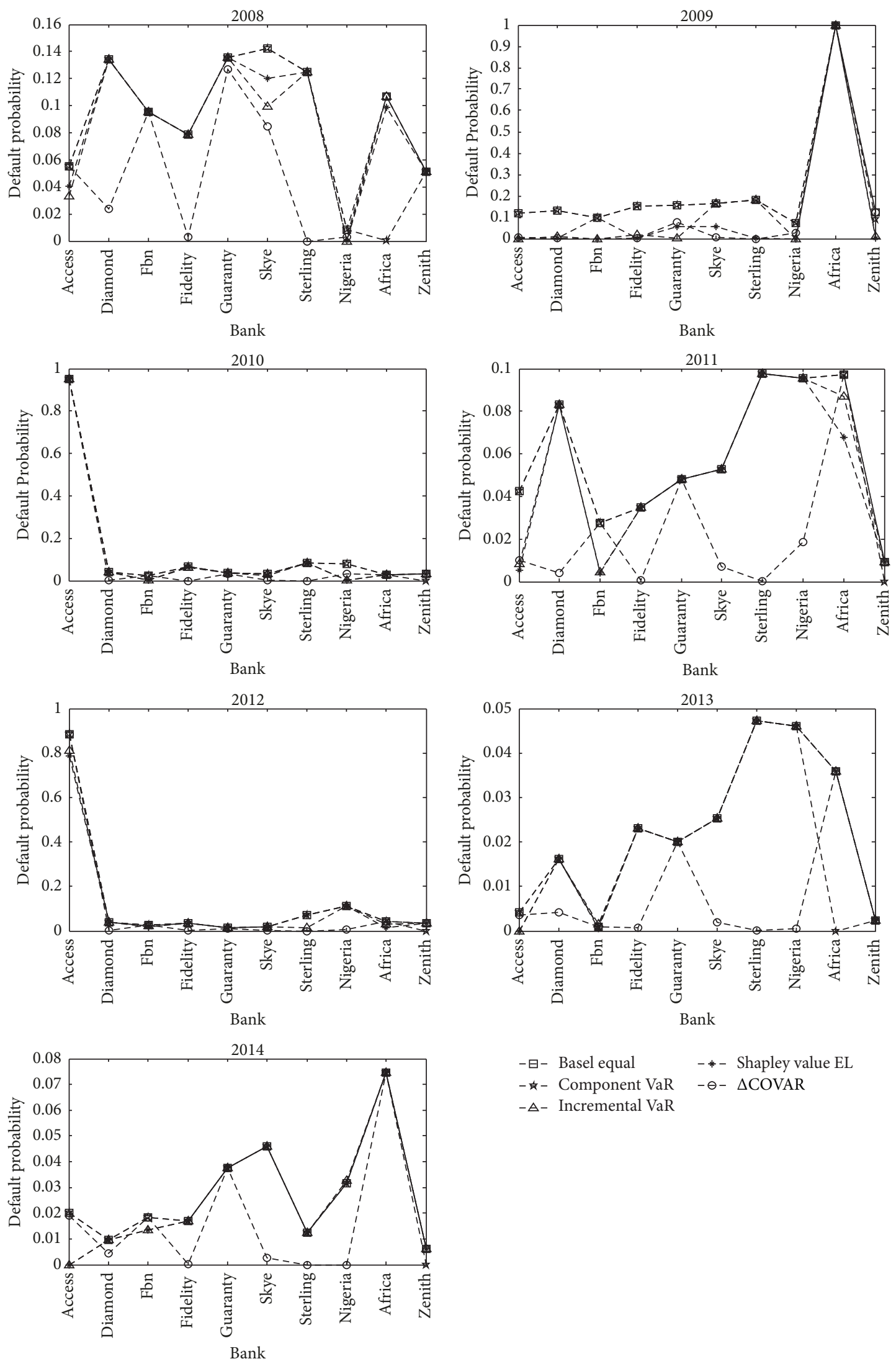

$$
\begin{array}{ll}
\text { - }- \text { Basel equal } & -*-\text { Shapley value EL } \\
\text { - } \text { - Component VaR } & -\ominus-\Delta \text { COVAR } \\
\text {-A- Incremental VaR } &
\end{array}
$$

$$
\begin{array}{ll}
\text { - }- \text { Basel equal } & -*-\text { Shapley value EL } \\
\text { - } \text { - Component VaR } & -\ominus-\Delta \text { COVAR } \\
\text { - } \Delta-\text { Incremental VaR } &
\end{array}
$$

FIGURE 4: Individual bank total default probabilities under macroprudential capital requirements for the entire sample of 2008-2014. Within the banking system, $\triangle$ COVAR downsizes the average probability of default the most. 
both the average default probability of individual institutions and multiple banks defaults can be substantially reduced, with $\triangle \mathrm{CoVaR}$ decreasing the average default probability the most. The findings suggest that risk allocation mechanisms can improve the stability of the system and regulate the financial system from a macroprudential dimension. The macroprudential capital allocation mechanisms work as an instrument of prudent bank regulation and importantly can reduce the risk of banks as well as the risk of the banking system.

The approach of estimating bilateral exposure matrix in the present paper assumes that the topology of the interbank network is complete network and does not reproduce incomplete interbank market. Depending on the actual network structure this may negatively or positively bias the results. In the future work, we can adopt the maximum entropy estimation method [19] and minimum density approach [37] to estimate the bilateral exposure matrix, and then we can give an interval value of macroprudential capital allocation, which will be more practical.

\section{Conflicts of Interest}

The authors declare that they have no conflicts of interest.

\section{Acknowledgments}

The authors acknowledge the support from the National Natural Science Foundation of China under Grant no. 71371046.

\section{References}

[1] P. Brämer, H. Gischer, and C. Lücke, "A simulation approach to evaluate systemic risk," European Journal of Political Economy, vol. 34, pp. S53-S64, 2014.

[2] D. Bisias, M. Flood, A. W. Lo, and S. Valavanis, "A survey of systemic risk analytics," Annual Review of Financial Economics, vol. 4, pp. 255-296, 2012.

[3] G. Galati and R. Moessner, "Macroprudential policy - a literature review," Journal of Economic Surveys, vol. 27, no. 5, pp. 846878, 2013.

[4] E. Cerutti, S. Claessens, and L. Laeven, "The use and effectiveness of macroprudential policies: New evidence," Journal of Financial Stability, vol. 28, pp. 203-224, 2015.

[5] M. Ebrahimi Kahou and A. Lehar, "Macroprudential policy: A review," Journal of Financial Stability, vol. 29, pp. 92-105, 2017.

[6] A. Lehar, "Measuring systemic risk: A risk management approach," Journal of Banking \& Finance, vol. 29, no. 10, pp. 2577-2603, 2005.

[7] S. G. Hanson, A. K. Kashyap, and J. C. Stein, "A macroprudential approach to financial regulation," Journal of Economic Perspectives (JEP), vol. 25, no. 1, pp. 3-28, 2011.

[8] P. Jorion, Value at Risk: The New Benchmark for Managing Financial Risk, McGraw-Hill, New York, NY, USA, 2007.

[9] T. Adrian and M. K. Brunnermeier, "CoVaR," American Economic Review, vol. 106, no. 7, pp. 1705-1741, 2016.

[10] L. S. Shapley, "A Value for $n$-Person Games," in Contributions to the Theory of Games II, Annals of Mathematics Studies, H. W. Kuhn and A. W. Tucker, Eds., vol. 28, pp. 307-317, Princeton University Press, Princeton, NJ, USA, 1953.
[11] L. Eisenberg and T. H. Noe, "Systemic risk in financial systems," Management Science, vol. 47, no. 2, pp. 236-249, 2001.

[12] F. Caccioli, M. Shrestha, C. Moore, and J. D. Farmer, "Stability analysis of financial contagion due to overlapping portfolios," Journal of Banking \& Finance, vol. 46, no. 9, pp. 233-245, 2014.

[13] S. Gualdi, G. Cimini, K. Primicerio, R. Di Clemente, and D. Challet, "Statistically validated network of portfolio overlaps and systemic risk," Scientific Reports, vol. 6, no. 1, Article ID 39467, 2016.

[14] F. Allen and D. Gale, "Financial contagion," Journal of Political Economy, vol. 108, no. 1, pp. 1-34, 2000.

[15] X. Freixas, B. M. Parigi, and J.-C. Rochet, "Systemic risk, interbank relations, and liquidity provision by the Central Bank," Journal of Money, Credit and Banking, vol. 32, no. 4, pp. 611-638, 2000.

[16] P. Gai and S. Kapadia, "Contagion in financial networks," Proceedings of the Royal Society A Mathematical, Physical and Engineering Sciences, vol. 466, no. 2120, pp. 2401-2423, 2010.

[17] D. Acemoglu, A. Ozdaglar, and A. Tahbaz-Salehi, "Systemic risk and stability in financial networks," American Economic Review, vol. 105, no. 2, pp. 564-608, 2015.

[18] P. Glasserman and H. P. Young, "How likely is contagion in financial networks?" Journal of Banking \& Finance, vol. 50, pp. 383-399, 2013.

[19] C. Upper, "Simulation methods to assess the danger of contagion in interbank markets," Journal of Financial Stability, vol. 7, no. 3, pp. 111-125, 2011.

[20] A. Lubloy, "Domino effect in the Hungarian interbank market," Mimeo, 2005.

[21] H. Elsinger, A. Lehar, and M. Summer, "Using market information for banking system risk assessment," International Journal of Central Banking, vol. 2, pp. 137-166, 2006.

[22] L. C. G. Rogers and L. A. M. Veraart, "Failure and rescue in an interbank network," Management Science, vol. 59, no. 4, pp. 882898, 2013.

[23] L. Frisell, M. Holmfeld, O. Larsson, and M. Omberg, "Statedependentcontagion risk: using micro data from Swedish banks," Mimeo, 2007.

[24] F. Caccioli, J. D. Farmer, N. Foti, and D. Rockmore, "Overlapping portfolios, contagion, and financial stability," Journal of Economic Dynamics and Control, vol. 51, pp. 50-63, 2015.

[25] C. Gauthier, A. Lehar, and M. Souissi, "Macroprudential capital requirements and systemic risk," Journal of Financial Intermediation, vol. 21, no. 4, pp. 594-618, 2012.

[26] C. H. Furfine, "Interbank exposures: Quantifying the risk of contagion," Journal of Money, Credit and Banking, vol. 35, no. 1, pp. 111-128, 2003.

[27] C. Upper and A. Worms, "Estimating bilateral exposures in the German interbank market: is there a danger of contagion?" European Economic Review, vol. 48, no. 4, pp. 827-849, 2004.

[28] I. van Lelyveld and F. R. Liedorp, "Interbank contagion in the Dutch banking sector:a sensitivity analysis," International Journal of Central Banking, vol. 2, p. 2, 2006.

[29] S. Wells, "Financial interlinkages in the United Kingdom's interbank market and the risk of contagion," Bank of England Working Paper No. 230, 2004.

[30] P. E. Mistrulli, "Assessing financial contagion in the interbank market: maximum entropy versus observed interbank lending patterns," Journal of Banking \& Finance, vol. 35, no. 5, pp. 11141127, 2011. 
[31] C.-P. Georg, "The effect of the interbank network structure on contagion and common shocks," Journal of Banking \& Finance, vol. 37, no. 7, pp. 2216-2228, 2013.

[32] T. Lux, "Emergence of a core-periphery structure in a simple dynamic model of the interbank market," Journal of Economic Dynamics and Control, vol. 52, pp. A11-A23, 2015.

[33] T. Xu, J. He, and S. Li, "A dynamic network model for interbank market," Physica A: Statistical Mechanics and its Applications, vol. 463, pp. 131-138, 2016.

[34] M. Bluhm, E. Faia, and J. P. Krahnen, "Endogenous banks' networks, cascades and systemic risk," SSRN, 2014.

[35] R. C. Merton, "On the pricing of corporate debt: the risk structure of interest rates," Journal of Finance, vol. 29, pp. 449470, 1974.

[36] S. Liao, E. Sojli, and W. W. Tham, "Managing systemic risk in The Netherlands," International Review of Economics \& Finance, vol. 40, pp. 231-245, 2015.

[37] K. Anand, B. Craig, and G. von Peter, "Filling in the blanks: network structure and interbank contagion," Quantitative Finance, vol. 15, no. 4, pp. 625-636, 2015. 


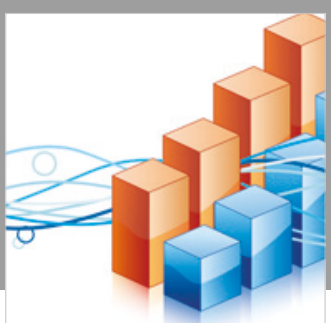

Advances in

Operations Research

\section{-n-m}
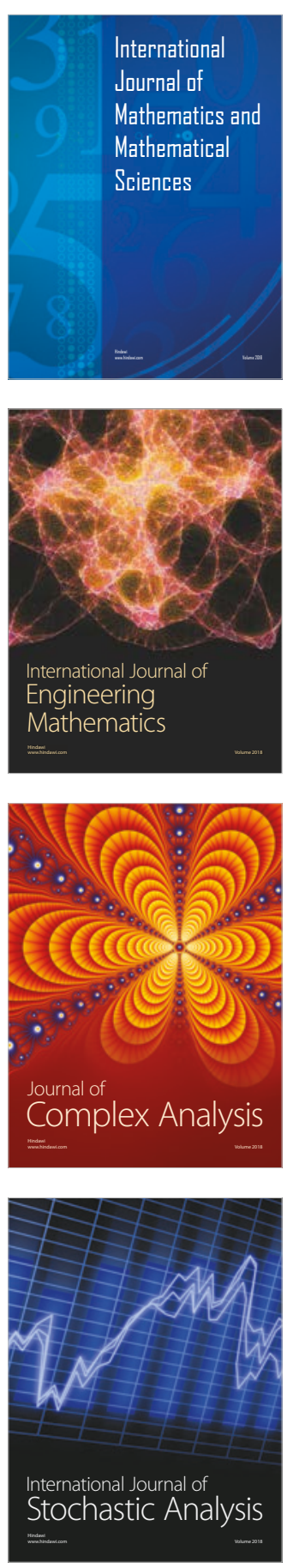
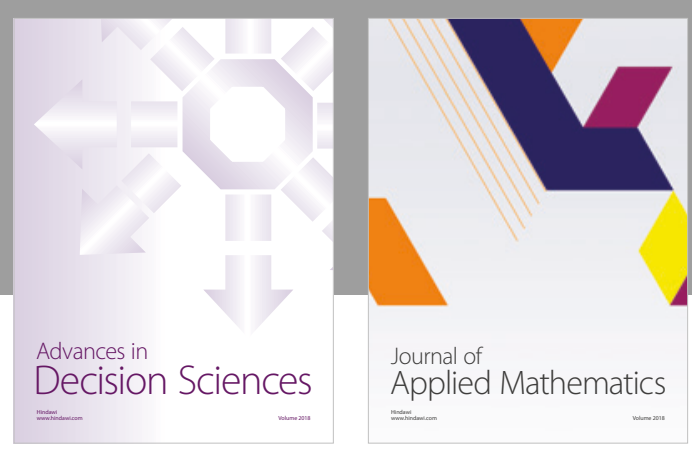

Journal of

Applied Mathematics
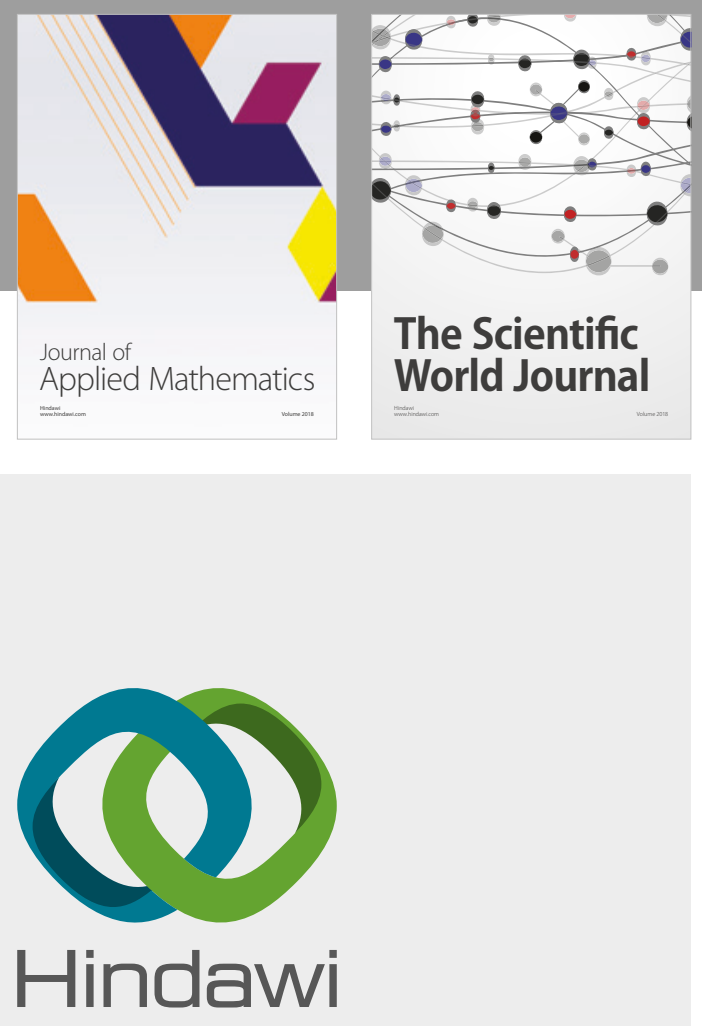

Submit your manuscripts at

www.hindawi.com

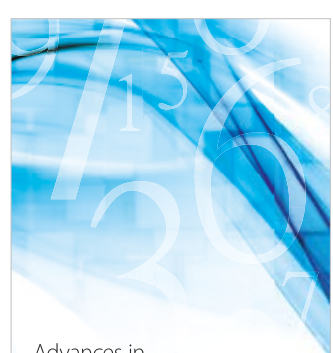

Advances in
Numerical Analysis
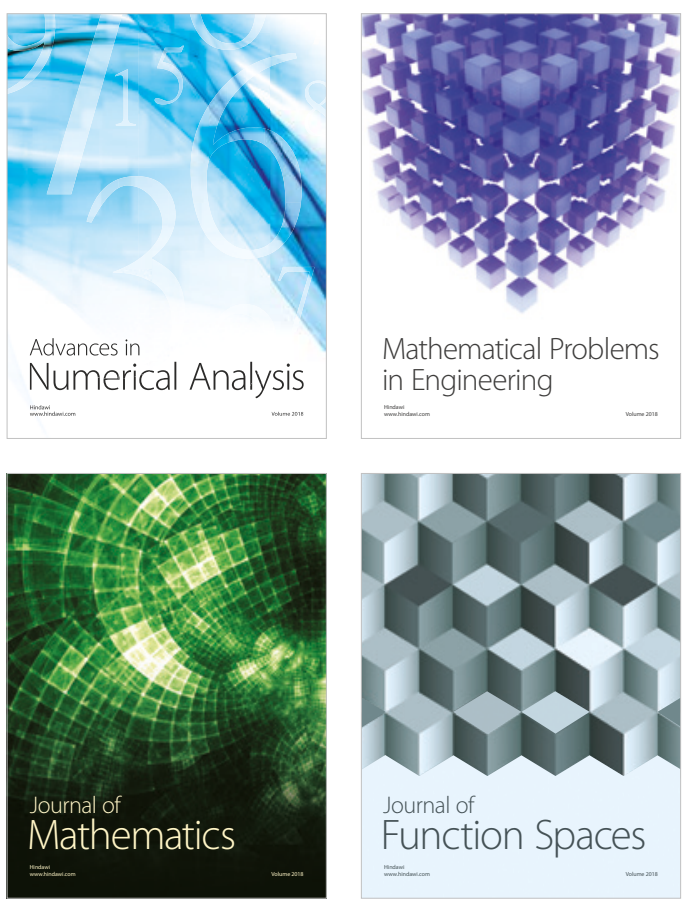

Mathematical Problems in Engineering

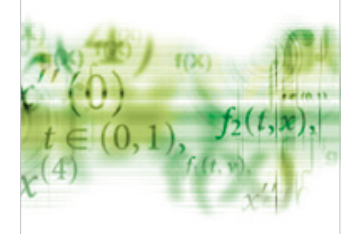

International Journal of

Differential Equations

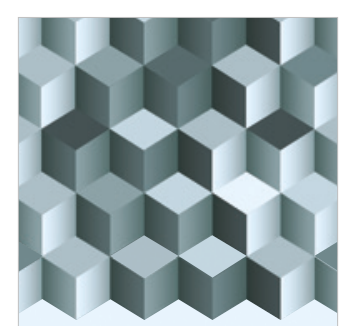

Journal of

Function Spaces
The Scientific

World Journal

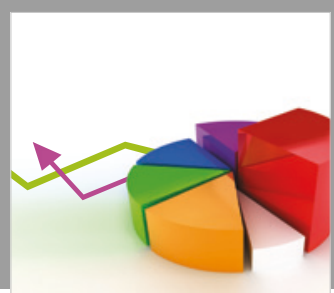

Journal of

Probability and Statistics
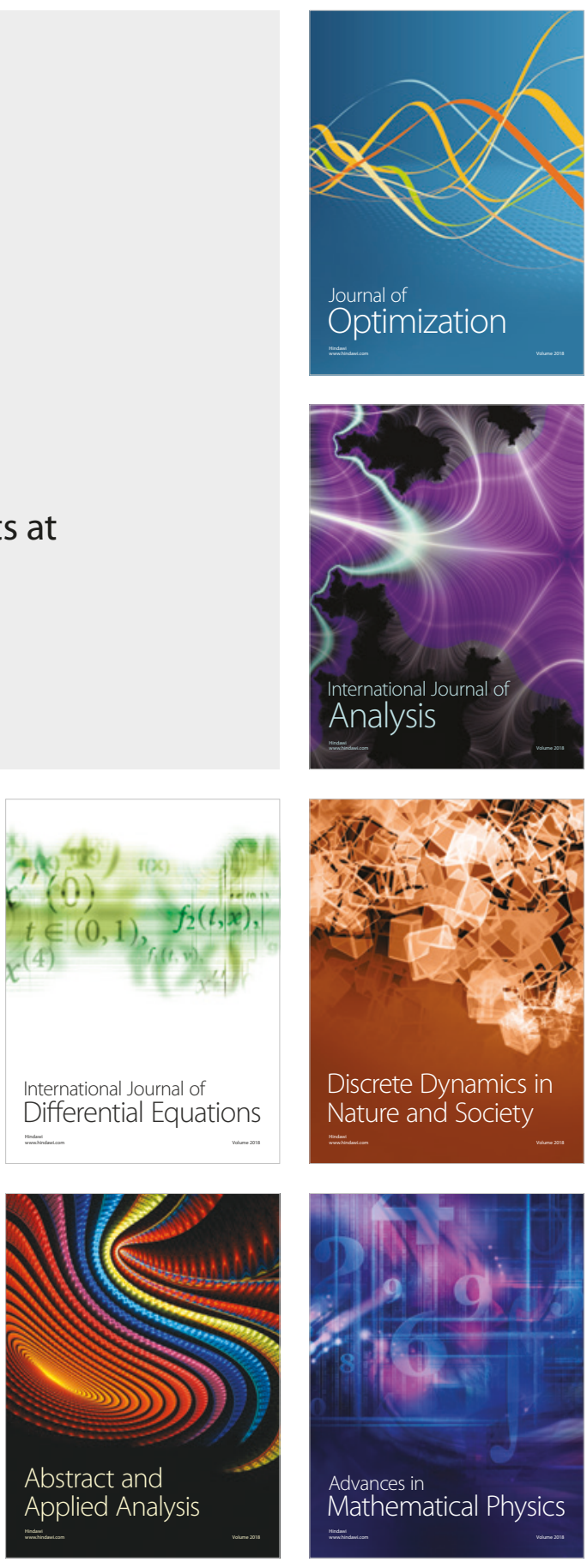